\title{
Attitudes to Research among Royal Free Psychiatric Trainees and Consultants
}

\author{
Chris Burford, Senior Registrar, Royal Free Hospital, London NW3
}

The promotion of interest in research has long been one of the objectives of psychiatric training, reaching its zenith in the now defunct academic DPM. The successor, the MRCPsych, has retained a research option even though the main stress is on clinical and scientific knowledge. The 1980 Handbook for Trainees and Inceptors noted that "The aim of the research option is to encourage trainees to acquire more searching and critical approaches and to foster interest in clinical data, literature, the teaching of psychiatric practice, and research."' Although the option has been used by "only a relatively small number of people", who have as a rule been "exceptionally able and energetic candidates", ${ }^{2}$ it has been retained in the newest version of the examination.

The numbers of trainees attempting research outside the examination have fluctuated considerably from an apparent decline in the 1970s to a "dramatic recovery in the last five years in the major centres". ${ }^{3}$ This last may be connected with the fact that with rising standards, the number of candidates for senior registrar posts who possess the MRCPsych regularly exceeds the number of posts available. A space for publications is a standard part of many application forms for senior registrar posts. Thus it is pointed out to trainees on rotation schemes that without some research to their name or some comparable distinguishing feature, they should not expect to be short-listed out of up to 30 or 40 applicants for the same job. Some of the pressures from job seeking familiar in medicine and surgery may have now spread to psychiatry.

Two changes in policy have occurred at the same time. The MRCPsych examination will soon have testing of background scientific knowledge in Part 2 of the examination, thus preventing the candidate from being able to put detailed scientific revision behind him or her to use the gap between Part 1 and Part 2 to start a research project. Meanwhile the restrictions on the number of registrar and senior registrar posts and a continuing effort by the College to raise the quality of training force difficult choices for trainees in allocating their time between service commitments and academic or other career interests.

Accordingly it was thought useful to elicit attitudes to the place of psychiatric research in training under the outgoing MRCPsych examination structure among the participants of one large training scheme. A confidential questionnaire was given to all psychiatric trainees at SHO and registrar level on the Royal Free rotation in December 1984. It was thought valuable to repeat this in the same format in December 1985 to check the consistency of the results, and also to send a parallel questionnaire to consultants at the same time, to compare different responses to these problems across the career structure.
The questionnaire, on one side of paper, sought responses to about seven questions including when the respondent thought was the best time to get first experience of a research project, what problems made this more difficult, how far trainees had got with a project and whether practical help would be valued. The consultants were asked comparable questions to the trainees.

\section{Results and discussion}

Samples

There were therefore three samples: all 1984 trainees in psychiatry, all 1985 trainees, and all 1985 consultants involved in the psychiatric training rotation. All trainees in psychiatry in both samples, and $96 \%$ of the consultants $(24 / 25)$ returned their questionnaires within three months of the survey dates. Where figures are given in percentages this is for the purpose of a broad comparison between the three samples and variations of less than $10 \%$ may be a random effect.

In 1984 there were 28 trainees. By December 1985 the rotation had expanded to 32 , partly due to the inclusion of two registrar research posts. In 1984 over half of all trainees were between Part 1 and Part 2 with only $18 \%$ post membership. By 1985 the distribution was more even with one third pre-part 1 and the proportion post membership had risen to a quarter, a probable reflection of the shifting job market.

\section{Optimum starting time for research}

The first two questions attempted to distinguish respectively when respondents thought was the best time to start research and when was the time they would personally prefer to start, or have preferred to start. Trainees were broadly similar in their replies to these two questions except that in 1984 where there were discrepancies, trainees were more likely to say they should have started their research earlier than the 'best' time.

Answers to the question about the preferred time of starting research, from 27 out of 28 trainees in 1984 and all 32 trainees in 1985, are summarised in the table as percentage of respondents. These are compared with the consultants' view of the best time to start research.

Consultant replies were closely similar which was interesting since some of them would have trained when expectations about the career structure in psychiatry were rather different.

The main feature of the results is the large body of opinion in all samples in favour of starting research after Part 1 and before Membership. If the figures in favour of starting before Part 1 are included, the total in favour of 
TABLE
Starting time for research

\begin{tabular}{lccc}
\hline & \multicolumn{2}{c}{$\begin{array}{c}\text { Trainees 'preferred' } \\
\text { Percentage of respondents } \\
1985\end{array}$} & $\begin{array}{c}\text { Consultant 'best' } \\
1985\end{array}$ \\
& 1984 & 13 & 21 \\
\hline Senior Registrar & 11 & 13 & 12.5 \\
Research Post & 19 & 31 & 17 \\
After membership & 15 & 16 & 54 \\
After Part 1 & 48 & 50 & 12.5 \\
Before Part 1 & 15 & 6 & \\
\hline
\end{tabular}

(Most respondents gave only one answer: all the double answers by trainees in 1985 included mention of a research post option suggesting greater interest in this possibility).

starting research before membership is $63 \%$ and $56 \%$ for trainees and $67 \%$ for consultants.

By 1985 two research posts for registrars had arrived on the rotation and trainees in the 1985 sample showed a noticeable increase in interest in a research post, unlike the consultants who gave relatively greater weight to starting at senior registrar level. In 1985 trainees were asked as a supplementary question whether they would like to do a research post, to which $94 \%$ replied affirmatively.

\section{Difficulties}

All trainees and consultants answered the question, "What problems do you think make it more difficult to do research on the SHO/REG rotation? Ring all appropriate answers."

All but one trainee and all consultants identified problems in trainees doing research. Among the SHOs and registrars there was a broad consistency between the replies in 1984 and 1985. The four main problems noted in each year were "Lack of time" ( $93 \%$ and $88 \%$ respectively), "Selecting a project that can be fitted round clinical work" ( $71 \%$ and $81 \%$ ), "lack of a designated adviser for research" (57\% and $31 \%)$ and "getting large enough samples" (36\% and $34 \%$ ). The main difference was the reduction in the proportion noting a lack of a designated adviser for research.

The consultants echoed the registrars' perception of difficulties to a substantial degree and in most cases the relative emphasis on the problems was similar. There was slightly less consultant concern about lack of time and fitting a problem around clinical work, which were placed first equal (by $62.5 \%$ ). Unlike trainees, however, a noticeable proportion of consultants $(29 \%)$ believed there was a lack of personal interest by trainees in research, although only 4 and $6 \%$ respectively of trainees admitted to this.

In all groups only one fifth or less thought that it was a problem to find interested colleagues with whom you could collaborate, and under $12 \%$ thought ethical approval was a problem, while still less were concerned about background reading.
Consultants volunteered a larger number of observations about 'other' difficulties, perhaps as a result of greater experience. These included "lack of prepackaged initial projects", "stringent examination requirements necessitating course attendance", "lack of time myself", "obtaining finance", "lack of a broad enough intellectual base with medical/psychiatric training", "discouragement from NHS colleagues", and "learning to allocate the time that they have".

A trainee commented on "lack of continuity: to do any reasonably small project takes 2-3 years from planning and reading to conclusion". Another echoed this: "finding an encapsulated short term project which can be undertaken by one worker over a limited period (and which has a reasonable chance of success)". Other plaintive comments in 1984 included "lack of knowledge on my part and noone with the time or interest to sit down and help", and "getting started". In 1985 comments made by trainees included "one questions the universal requirement of having research on one's $\mathrm{CV}$ when one aspires to a clinical career", and difficulties included "taking exams", and, even more succinctly, "Money and Power!" The only trainee not to identify any specific problems had signed up for a supervised MPhil early in training.

\section{Attempts and failures}

When consultants were asked "What proportion of trainees would you estimate have tried to start a research project since joining the rotation?", only 21 replied. 57\% of these guessed that roughly only $20 \%$ of trainees had tried to start. By contrast $54 \%$ of 1984 trainees said they had tried to start and $62.5 \%$ of 1985 trainees. This figure is approximately twice the consultants' estimation overall.

Trainees were asked about the progress of these research projects with a prompted choice. In both years two subjects who had 'tried' to start a project had not actually got started, bringing the proportion of project starters down to $46 \%$ and $56 \%$ of the two respective years.

Expressed as a percentage of the combined total of the 15 who claimed to have tried to start in 1984 and the 20 in 1985 , trainees had projects at the following stages (a few subjects gave more than one answer apparently because they were reporting on more than one project): $11 \%$ had not actually started, $20 \%$ had started a project but abandoned it, $26 \%$ had a project that was 'temporarily suspended', $14 \%$ had a project that was being designed, $11 \%$ were collecting data, $14 \%$ were analysing their results, $9 \%$ had completed analysis and no one had a project published that they had started on the rotation, despite the fact that by 1985 one quarter of trainees were post membership.

Of those who had tried to start, $66 \%$ in 1984 and $59 \%$ in 1985 had either failed to start at all, or had abandoned or suspended at least one of their projects.

As compared between the two years the picture was consistent with slightly more purposeful research activity in $1985,(37.5 \%$ with an active project at least at the design stage compared to $29 \%$ in the previous year). 
Help

When asked, "Would you be interested in ideas about practical ways of doing research that can be combined with clinical work at SHO/Reg level?", not surprisingly $96 \%$ of trainees in 1984 and $88 \%$ in 1985 said they would. The slightly lower figure for 1985 seemed to be associated with a few trainees who questioned the idea of having to do research before senior registrar level. Nevertheless the overall desire for practical help is clear.

This strongly felt need seemed to be answered in principle by the replies of consultants to the question, "Would you be willing to discuss with your juniors practical ways of doing research that could be combined with clinical work at SHO/ Registrar level?" To this $79 \%$ of consultants said they would against $21 \%$ who said "yes but it would be difficult" and none who refused outright. Even if the "Yes but" option is interpreted as a tactful negative, this appears to show a strongly sympathetic picture of consultant support to trainees' research efforts. What is not clear is whether this alone is sufficient to meet the trainees' needs. Nor does it make clear the extent to which the consultants expect trainees to overcome the hurdles themselves, and indeed regard it as part of the survival of the fittest that they should do so. The difficulties in the way of the trainee researcher are considerable.

\section{Comments and attitudes}

Some comments which flush out the statistics have already been noted in the section on difficulties. Trainees made a few other significant remarks.

In 1984 a trainee commented about whether her project was "temporarily suspended", "I would like to think so about the abandoned ideas. I'm afraid of it happening to the present one-lack of time". In 1985 the same trainee noted that "projects get so behind they get abandoned", and referred to two or three now in this category. In terms of the problem of getting large enough samples she thought that pilot studies might be satisfactory at trainee level. Another subject queried against her project marked as being 'analysed', "? to be abandoned because unsuccessful, or ? something retrievable to be published".

Consultants were specifically invited to make any further comments they wished and almost half did so, two writing thoughtful letters.

Consultant comments included "need time off rotation for research". "I believe some have a need to carry out research. They have to be facilitated at whatever stage they wish to begin. I do not believe that useful research is done by coercion." "As you can see I feel strongly that research is part of SR training and NOT SHO/Reg training. However, I would be as helpful as possible if an SHO/Reg wished to carry out a project." "Friern certainly encourages research, but many of the previous posts I have had experience of, one wouldn't know where to start." "I feel it is important to create an atmosphere of research and the expectation that trainees should do it. The main difficulty is to find suitable projects to do while doing a clinical job". "The six monthly rotation militates against research. Juniors should be able to elect to remain for a further six months to advance/complete a project." Only one person noted that "Registrars should be reminded of the research option for the MRCPsych".

In a letter one consultant expressed reservations about "the tendency of questionnaires to force the production of neatly tabulated results which are no substitute for the respondents being able to express their views as they experience them". In particular this commentator observed that "one of the problems with our subject is that in order to develop techniques for collecting data which allow for numerical analysis, we are in danger of either discovering things which are utterly trivial or forcing the emergence of results which are not in fact a reflection of whatever matter is being enquired into". The writer for example, wished to see "the concept of research extended into the production of coherent, consistent and carefully worked essays on clinical phenomena".

Another letter commented on the logistical problems of fitting into the mechanics of the rotation the ideal option of trainees being seconded to a research post for three to four months. It also noted the psychological problems that because many people attracted to psychiatry are primarily interested in the personal and human aspects of the subject and in developing their clinical skills, this may act against a positive interest in research.

\section{Conclusions}

Despite the inevitably arbitrary nature of a cross sectional questionnaire into something as complex as people's attitudes to psychiatric research, the results of these enquiries show a degree of face validity and consistency between the two trainee samples and the consultant sample, albeit perhaps shaded at times by a sense of the socially desirable responses.

The major finding from this training rotation was a widespread desire or sense of need to attempt, and a large number of reported attempts, to start a research project before the membership exam. A great discrepancy in the consultants' awareness of trainees' efforts at research was indicated but the explanation is not clear. Trainees may have over-estimated their attempts in their replies. Modesty or lack of confidence may have led trainees not to inform their consultant colleagues fully of their fragile hopes. They may have feared consultant concern about service commitments and been unaware of the extent of consultant willingness to support research as claimed in consultant answers to this questionnaires.

The overall picture is one of a disturbing half of all trainees' research projects failing in what is clearly a difficult environment for trainee research. Answers are not easy. By 1985 there was evidence of considerable trainee interest in doing a formal research post of the sort that had been established in that year, and of knowing better where to turn for guidance. Nevertheless such posts are in some cases temporary arrangements and cannot in themselves cater for all the trainees' research needs. 
Although consultants' replies showed a substantial willingness to give sympathetic support, general sympathy may not be enough. Nor was it clear how far in reality the proffered help might go. Some consultants may have reservations because of their greater concern that a trainee carries out clinical work properly, or may feel that conventional research at this level can be mechanical or opposed to a philosophical or dynamic approach to psychiatry. Some may feel that many of the difficulties for trainees doing research are inevitable and that too much aid might on the one hand create a climate pressing research onto trainees whose interests and abilities lie elsewhere, or on the other hand obscure a process of selection by which the fittest show that they can achieve despite the many obstacles. At the very least, senior colleagues may look for evidence that the trainee has intelligently sought out available sources of assistance, before he or she devotes personal time to helping the trainee. Regrettably therefore there was no reference to the helpful Hints on Research available from the College Research Committee (new edition March 1985) ${ }^{5}$ but even with the aid of these, or the courses the committee now organises periodically on research methods, it is debatable how far trainees can contribute to the conventions of serious modern psychiatric research without specific and fairly detailed support from their own consultants.

A second finding from the survey was the clear and strongly-held belief among both trainees and consultants that the best time to start research before becoming consultants was between Part I and Part II of the membership exams. Such a viewpoint is no doubt the result of many factors such as people's perception of appropriate psychiatric training, the situation of supply and demand in the market for senior registrar posts, and the syllabus of the membership exams. It is possible with the new examination structure that is being introduced, which requires the candidate to retain familiarity with a wide amount of detailed scientific knowledge right up to Part II, that trainees will face a riskier gamble in initiating a research project at this time, at the possible expense of jeopardising their Part II results. No doubt the most able will by definition achieve this with distinction and will prosper in an increasingly competitive job market by means of longer CVs with more publications on them. For the majority it is not clear whether fewer will attempt research or more will fail, or possibly the new syllabus will promote better and more scientific research. Whether these different outcomes are a good or a bad thing can only be debated in the light of the broader issues of the shape of British psychiatry. What is clear is that research among psychiatric trainees is an area subject to many pressures and many difficulties, which is unlikely to remain static over the coming years.

\section{ACKNOWLEDGEMENTS}

I would like to thank Dr Anthony Mann, Reader in Psychiatry at the Royal Free Hospital, for his advice on the design and presentation of the study, and all the SHO and registrar psychiatric trainees, and the psychiatric consultants of the Royal Free and psychiatrically related hospitals, who replied to these questionnaires so amiably, with such a high response rate and with such detailed and careful thought.

REFERENCES

${ }^{1}$ Bewley, T. \& Mahapatra, S. (1980) (eds.) Handbook for Inceptors and Trainees in Psychiatry. Royal College of Psychiatrists.

${ }^{2}$ WorkIng PARTY for the REVIEW OF THE MRCPSYCH (1985) Report to the Court of Electors. Royal College of Psychiatrists.

${ }^{3}$ ShiwACH, R. H. \& MURRAY, R. M. (1986) Does psychiatric research need training? Editorial, British Journal of Hospital Medicine, July, p. 11

${ }^{4}$ Crammer, J. L. \& Freeman, C. P. (1985) Hints on Research. Royal College of Psychiatrists Research Committee.

\section{Memorial Lecture}

The Trustees of The Child Guidance Trust have announced that they propose to establish a Memorial Lecture to reflect the personal and professional commitment to child and family mental health, both at home and in the developing countries, of Robina Scott Addis, OBE.

The management of the Memorial Lecture will be the responsibility of The Guild Guidance Trust whose members include representatives of psychiatry, psychology, psychotherapy, education and psychiatric social work Robina Adis was herself a founder member of The Trust and qualified as a psychiatric social worker in 1933, just prior to her appointment at Canonbury Clinic (which later became The Child Guidance Training Centre).

The Trustees aim to raise $£ 5,000$ to endow this Memorial Lecture, which will become a regular part of the activities of The Child Guidance Trust. Contributions should be made payable to 'The Robina Addis Memorial Lecture' and sent to: Gordon Howe, Honorary Treasurer, The Child Guidance Trust, Rolls House, 7 Rolls Building, Fetter Lane, London EC4A INL. 